\title{
Management strategy for hematological malignancy patients with acute respiratory failure
}

\author{
Li Jiang ${ }^{1}$, Qunfang Wan ${ }^{1}$ and Hongbing $\mathrm{Ma}^{2^{*}}$ (1)
}

\begin{abstract}
Acute respiratory failure (ARF) is still the major cause of intensive care unit (ICU) admission for hematological malignancy (HM) patients although the advance in hematology and supportive care has greatly improved the prognosis. Clinicians have to make decisions whether the HM patients with ARF should be sent to ICU and which ventilation support should be administered. Based on the reported investigations related to management of HM patients with ARF, we propose a selection procedure to manage this population and recommend hematological ICU as the optimal setting to recuse these patients, where hematologists and intensivists can collaborate closely and improve the outcomes. Moreover, noninvasive ventilation (NIV) still has its own place for selected HM patients with ARF who have mild hypoxemia and reversible causes. It is also crucial to monitor the efficacy of NIV closely and switch to invasive mechanical ventilation at appropriate timing when NIV shows no apparent improvement. Otherwise, early IMV should be initiated to HM with ARF who have moderate and severe hypoxemia, adult respiratory distress syndrome, multiple organ dysfunction, and unstable hemodynamic. More studies are needed to elucidate the predictors of ICU mortality and ventilatory mode for HM patients with ARF.
\end{abstract}

Keywords: Hematological malignancy, Acute respiratory failure, Intensive care unit, Ventilation

\section{Introduction}

Hematologic malignancy (HM) is neoplastic myeloid or lymphoid disease, including acute and chronic leukemia, lymphoma, myeloma, as well as myelodysplastic syndrome and myeloproliferative neoplasm $[1,2]$. The prognosis of patients with HM has been dramatically improved by chemotherapy and hemopoietic stem cell transplantation [3]. However, therapy-associated pulmonary complications compose $20 \%$ undesirable outcomes [3]. Due to pneumonia, sepsis, leukemia infiltration or graft vs. host disease, acute respiratory failure (ARF) is a common pulmonary complication for patients with HM

*Correspondence: hongbingma@foxmail.com

${ }^{2}$ Department of Hematology, West China Hospital, Sichuan University, Chengdu, China

Full list of author information is available at the end of the article as well as the major reason for intensive care unit (ICU) admission $[4,5]$. The mortality varied from 30 to $70 \%$ in different reports $[4,6]$. Confronting HM patients with ARF in clinical setting, the clinicians have to make decisions about the next procedures. Do they need treatment in an ICU? Which kind of respiratory support should be selected for the patients, noninvasive ventilation (NIV) or invasive mechanical ventilation (IMV)? In this review, based on the results of different investigations related to management of $\mathrm{HM}$ patients with ARF, which is defined as $\mathrm{PaO}_{2}<60 \mathrm{mmHg}$, or tachypnea $>30 / \mathrm{min}$, or $\mathrm{SpO}_{2}<90 \%$ on room air, or the ratio of arterial oxygen partial pressure to fractional inspired oxygen $\left(\mathrm{PO}_{2} /\right.$ $\left.\mathrm{FiO}_{2}\right)<300$, or labored breathing, or respiratory distress, or dyspnea at rest [7-10]we propose a selection strategy to help manage this population and hopefully improve their outcomes. 


\section{Critical care for HM patients with ARF}

Undoubtedly, ICU is the best place for critically ill HM patients with ARF, because they can provide high level of life support [3]. As a result, the outcomes in ICU were better than in ward $[11,12]$. Respiratory management in ICU was also related to successful extubation for HM with ARF who received mechanical ventilation [13]. In addition, earlier ICU admission (time between ARF onset and ICU admission less than $24 \mathrm{~h}$ ) leads to better hospital survival [14]. Conversely, delayed admission (more than 2 days) increased the morality of this population [15-17]. However, ICU resource is limited with high cost, HM patients usually spend more critical care resource than non-HM patients [18]. It is also unethical to send end-oflife patients to ICU only for prolonging time. Therefore, it is necessary to screen eligible patients based on reasonable triage policy.

In clinical practice, the determination is mainly made on clinical judgement of physicians. However, some investigators hold that the admission of HM patients to ICU should be determined by objective mortality prediction model rather than clinical experience [18]. The former includes Acute Physiology and Chronic Health Evaluation (APACHE) II scores, the Sequential Organ Failure Assessment (SOFA), and the Simplified Acute Physiology Score (SAPS) II which could predict ICU mortality accurately [19-21]. Namendys-Silva et al. reported the ICU mortality of HM patients who had three or more organ dysfunctions and a SOFA score of 10 points were $70.1 \%$ and $80 \%$, respectively. Consequently, HM patients with ARF who had two or fewer organ dysfunctions or a SOFA score of less than 10 points were recommended to ICU admission [6]. However, several studies also demonstrated these scores neither well discriminate the illness severity nor predict the prognosis of this population [2224]. Azoulay et al. proposed 10 subgroups of HM patients who unlikely benefited from ICU management, but they also emphasized the criteria should not be an obstacle for ICU admission referral, because decision making could not be completely objective; furthermore, new emerging evidence may change our practice [15]. Currently, a feasible way to evaluate the prognosis should be based on combination of clinical experience and matched results of clinical studies as well as the HM patients and the relatives' willing. Prioritization of ICU admission should be given to those who probably benefit most from critical care. More studies are needed to clarify the value of different score systems in predicting the ICU outcome as well as the criteria of defining early ICU admission for HM patients with ARF.

An ideal ICU for HM with ARF patients should be hematologic ICU, where hematologist, intensivist and respiratory therapist can collaborate closely to provide the optimal critical care [15, 25]. The hematologists are good at addressing HM and related complications, while intensivists and respiratory therapists are accomplished in respiration and circulation support to stabilize patients $[15,18]$. They can discuss and make decisions together for HM patients without time and space limitations. However, to our knowledge, most tertiary hospitals in China have general ICUs instead of hematological ICUs. The diagnosis and treatment are split into two parts in two departments, intensivists communicate with hematologist through intermittent and untimely interviews, which can't guarantee the HM patients at ICU receive the same level of hematological expertise. In fact, many newly diagnosed patients even with life-threatening $\mathrm{HM}$-associated complications had a high survival when they initiate chemotherapy in the ICU [26]. Consequently, when hematological ICU is not available, it plays a crucial role in improving the survival of HM patients with ARF to establish effective and sustained collaboration between hematologist and intensivist.

\section{Ventilation mode for HM with ARF}

Oxygen alone, NIV and IMV compose the common types of respiratory ventilation for HM with ARF. Due to the immune deficiency, HM patients with ARF had a high mortality of $50-70 \%$ when they received IMV $[27,28]$; therefore, avoiding IMV is a critical strategy to improve the prognosis of this population. NIV, including continuous positive airway pressure (CPAP) and bi-level positive airway pressure (BiPAP), has been recommended for Chronic obstructive pulmonary disease exacerbation, cardiac pulmonary edema and immunosuppressed patients, which can reduce the need of intubation and related complications [27, 29-31]. Usually, BiPAP is better for patients with type II respiratory failure [4].

\section{NIV for HM with ARF}

Several studies have demonstrated NIV can benefit HM patients with ARF (Table 1) [3, 32-40]. Conti et al. evaluated the efficacy of BiPAP among $16 \mathrm{HM}$ patients with ARF $(87 \pm 22$ of arterial partial pressure of oxygen to fraction of inspired oxygen, $\left.\left(\mathrm{PaO}_{2} / \mathrm{FiO}_{2}\right)\right)$ in a pilot study. 15/16 patients showed improvement in blood gas and respiration. 5 died and 11 were discharged in good condition. It indicated NIV was a feasible alternative of IMV for HM patients with ARF [34]. Gristina et al. analyzed retrospectively 1302 patients with $\mathrm{HM}$ and ARF in 158 Italian ICUs. 21\% patients received NIV and more than half $(54 \%)$ avoided intubation. The mortality 


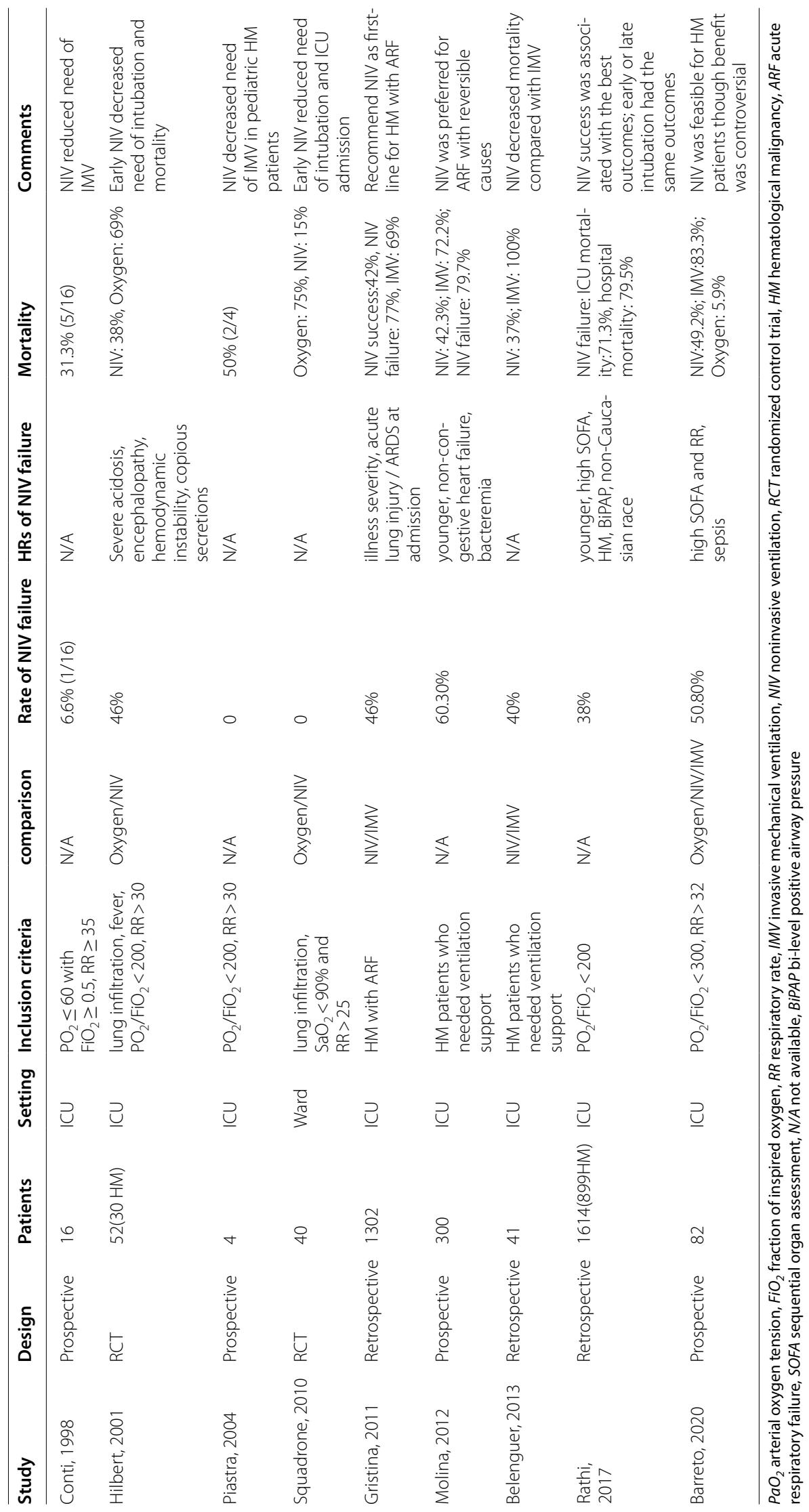


in NIV group was significantly lower than immediate IMV and IMV after NIV failure (42\% vs. $69 \%$ and $77 \%$, respectively). Delayed IMV was related to a little higher mortality than immediate IMV but without significant difference. Based on these facts, they suggested NIV as first line for HM with ARF [32]. Multivariate analysis indicated illness severity and acute lung injury / ARDS at admission were risk factors of NIV failure [32]. Belenguer et al. [36] analyzed retrospectively $41 \mathrm{HM}$ with ARF and compared the outcome of IMV (35 patients) and NIV(6 patients) group in ICU. The mortality was $100 \%$ and $37 \%$ in the IMV and NPPV group, respectively. Similar outcomes were verified in children HM with ARF and other studies [33]. Therefore, NIV substantially decreases the intubation rate and mortality rate of HM patients with ARF.

However, inconsistent data has also showed NIV may not protect HM with ARF (Table 2) [1, 7, 8, 41-44]. In a retrospective study, Depuydt et al. enrolled $166 \mathrm{HM}$ patients with ARF who required MV in ICU. Based on an analysis of NPPV and IMV with a ratio of 1:2, no difference in mortality was found between 2 groups [44]. However, $\mathrm{PO}_{2} / \mathrm{FiO}_{2}$ in NIV was lower than IMV (72 vs. 147, respectively), indicating NIV group had a high risk of intubation and mortality. Therefore, the baselines in two groups are not comparative. In 2010, the same team compared the efficacy of NPPV, IMV and oxygen alone among 137 HM with ARF. The ICU mortality was $71 \%$, $63 \%$, and $32 \%$ as well as in-hospital mortality was $75 \%$, $80 \%$, and $47 \%$ in NPPV, IMV and oxygen alone, respectively $(P=0.001)$. The outcomes were determined by the severity of disease rather than the respiratory support type. NIPPV seems to be unprotective to HM with ARF [43]. In a randomized trial, Lemiale et al. enrolled 374 immunosuppressed patients (including $283 \mathrm{HM}$ ) with ARF $\left(\mathrm{PO}_{2} / \mathrm{FiO}_{2} 200-300\right)$ and compared NIV with oxygen therapy. Compared with oxygen therapy, early NIV did not reduce the 28-day mortality either overall or in subgroups $(24.1 \%$ and $27.3 \%$ in NIV and oxygen, respectively) and subsequent intubation (38.2\% and $44.8 \%$ in NIV and oxygen, respectively). The authors also acknowledged the lower mortality in oxygen group than expected may limit the power to draw a significant difference in mortality, and the respiratory condition was less severe considering the RR of 25-27 breaths/min [8]. When only $380 \mathrm{HM}$ patients were analyzed prospectively, they still found no benefit could be achieved from NIV compared to oxygen alone [7]. Moreover, many studies revealed a high NIV failure rate of $54-75 \%$ in HM with ARF [1, 41, 45], those who failed NIV had a similar or even worse prognosis in patients who initially received IMV $[32,37$, $39,46]$.

\section{IMV for HM with ARF}

Although IMV is associated with high mortality of HM patients in ICU [2, 13, 28, 42, 47-49], some studies also indicated early IMV may decrease mortality [37, 44, 50]. Molina et al. enrolled $300 \mathrm{HM}$ with ARF in a prospective, multicenter study. The patients who received IMV after INV failure had a higher mortality than those who received IMV initially $[37,51]$. In a randomized trial, Wermke et al. recruited 86 allogeneic hematopoietic stem cell transplantation (allo-HSCT) patients with ARF and compared NIV with oxygen alone, NIV did not reduce the need of intubation and admission to ICU as well as mortality. All intubated patients after NIV failure died. A limitation is that $16 / 17$ patients failing on oxygen alone were switched to NIV, which may attenuate the effect of NIV [42]. However, it can be inferred from the studies early IMV may benefit some patients. In addition, it was reported IMV within $24 \mathrm{~h}$ of ICU admission was associated with a better outcome [44, 50]. Most importantly, the critical care level and IMV therapy have been improved tremendously in the past 2 decades and developed continuously, as revealed by the huge reduction of the mortality in ICU and hospital [52]. Many classic predictors, such as neutropenia, APACHE II score, age, and allo-HSCT, have lost their predictive value for HM in ICU $[15,48,53]$. Therefore, early IMV should be the first-line option for this population who have high risk of NIV failure.

Several risk factors that could predict NIV failure have been identified. Barreto et al. [35] implemented IMV, NIV and oxygen only to $82 \mathrm{HM}$ with ARF based on $\mathrm{PaO} 2 / \mathrm{FiO} 2$ and clinical judgement, 59 (72\%) patients received NIV, and 30 of them (58.2\%) need intubation. The mortality was $83.3 \%, 49.2 \%$ and $5.9 \%$ in IMV, NIV and oxygen only, respectively. NIV failure was associated with high SOFA( $>7$ points), RR ( $>34$ breaths $/ \mathrm{min})$ and sepsis. IMV is recommended if one of these factors exists. Depuydt et al. appealed to IMV for HM with ARF who were excluded from NIV, especially for those whose admission to ICU was driven by sepsis [44]. Other risk factors of NIV failure were also reported in different investigations, which included need for vasopressor, longer delay between admission and NIV, acute respiratory distress syndrome (ARDS), hepatic failure, hemodialysis, high APACHE II and SAPS II score, et al. [4, 35, $37,39,41,45,54-56]$.

\section{The selection of ventilation mode for HM with ARF}

Overall, Conflicting conclusions derive from the heterogeneity of different studies. The design, NIV timing and setting, ICU admission policy, inclusion criteria, etiology and organ failure varied among the investigations $[5,54]$. 


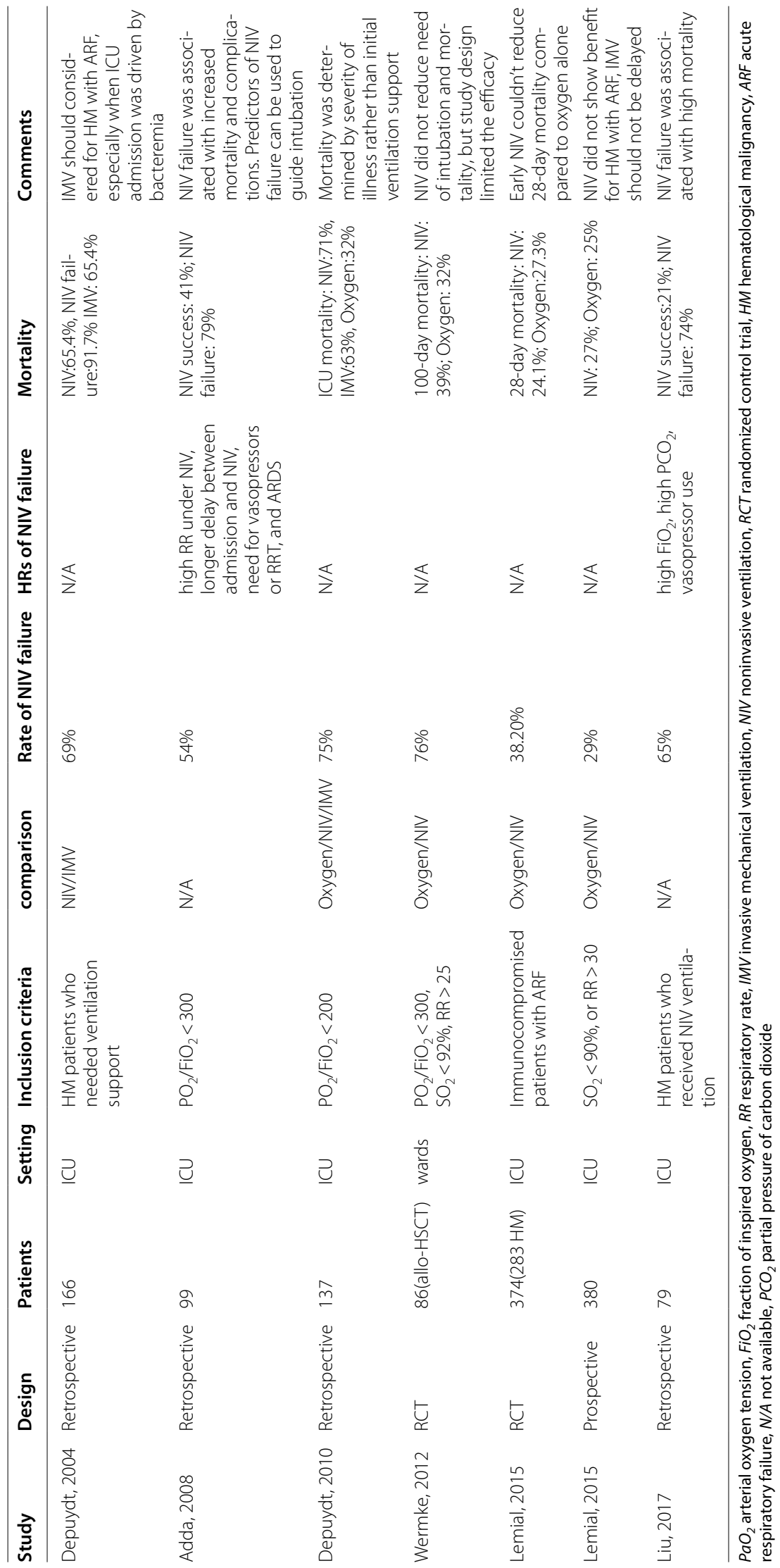


Azoulay et al. [57] believed, due to the increasing progress in IMV and remarkable reduced mortality of IMV, it is not necessary to implement NIV for HM patients with ARF. However, significant difference in mortality is still evident between NIV and intubation either in 2000 (50\% vs. 90\%) or in $2010(15 \%$ vs. $60 \%)$ although mortality rate decreases over time [57]. Based on the available data and our experience, NIV still has its own place for HM with ARF when it is initiated earlier and used for selected patients.

Squadrone et al. reported early use of CPAP in the ward can significantly reduce the need of ICU admission and subsequent intubation. $40 \mathrm{HM}$ patients with neutropenia and mild respiratory failure (200-300 of $\mathrm{PaO}_{2} /$ $\mathrm{FiO}_{2}$ ) were enrolled and assigned randomly to oxygen and CPAP group. The inclusion criteria included radiological evidence of bilateral pulmonary infiltration due to non-infectious causes, $\mathrm{SaO} 2<90 \%$ in room air, and respiratory rate $>25$ breaths/min, mortality rate was $75 \%$ and $15 \%$ in oxygen and CPAP, respectively [3]. Another randomized trial reported by Hilbert et al. also showed similar results in 52 immunosuppressed patients (including $30 \mathrm{HM}$ ) [38]. These results illustrate HM patients can benefit from NIV when ARF is mild, NIV may lost its potential value when ARF is severe [44]. In addition, selecting eligible HM patients plays critical role in increasing NIV success rate. As mentioned above, the patients who have no or few high risk of NIV failure may benefit most from the NIV.

Although the predictive indicators are not completely consistent and need more high-quality trials to prove, a comprehensive suggestion can be outlined. NIV is preferred for $\mathrm{HM}$ patients with $\mathrm{PaO}_{2} / \mathrm{FiO}_{2}>200$ or SO $2<90 \%$ and $\mathrm{RR}>25$ breaths/min, and those who have reversible etiology, such as cardiac pulmonary edema or refuse intubation [4, 37, 38, 54] (Fig. 1). In addition, careful adjustment of NIV administration in the first hours to improve patient tolerance and avoid leaks could result in better outcome [25], which emphasize the experience and organization of team group [4]. Usually, alleviation in dyspnea and improvement in artery blood gas analysis could be achieved within $2 \mathrm{~h}$ after NIV implementation if it was effective [58], improved $\mathrm{PaO}_{2} / \mathrm{FiO}_{2}$ after $1 \mathrm{~h}$ was a predictor of NIV success [56]. Consequently, close evaluation of NIV efficacy and early switch to IMV are critical when NIV is properly administered and shows no improvement (Fig. 1). In contrast, IMV should be the first option for those consciousness disorder, unstable hemodynamic, $\mathrm{PaO}_{2} / \mathrm{FiO}_{2}<200, \mathrm{RR}>35$ breaths/min, ARDS and multiple organ dysfunction (Fig. 1) [4, 35, 37, 39, 41, 45, 54, 57].

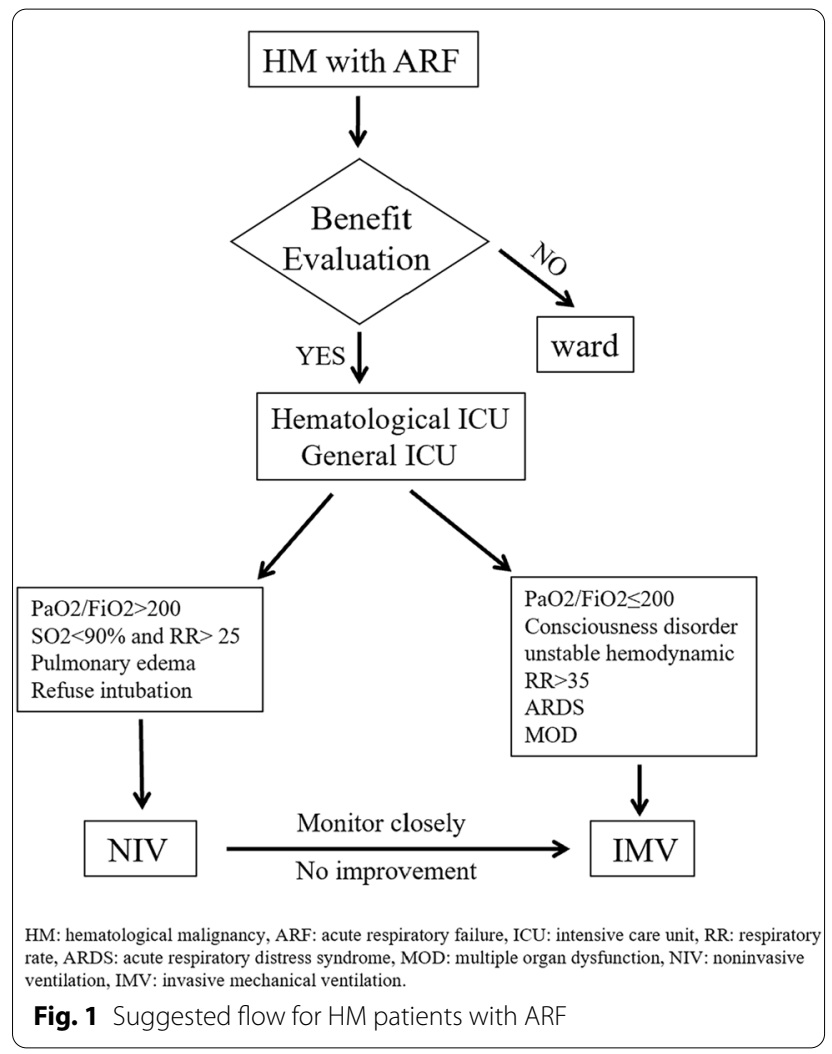

\section{Conclusions}

HM patients with ARF have a high mortality rate. Hematological ICU is the optimal place to rescue this patient population. Admission to ICU should be as early as possible when they may benefit from critical care by evaluation. Close collaboration among hematologists, intensivist, respiratory therapists and other physicians plays a pivotal role in providing high level of diagnosis and treatment and in producing better outcomes. NIV still has its own place for selected HM patients with ARF who have mild hypoxemia and reversible causes. It is also crucial to monitor closely the efficacy of NIV and switch to IMV at appropriate timing when NIV shows no apparent improvement. Otherwise, early IMV should be initiated to HM with ARF who have moderate and severe hypoxemia, ARDS, MOD, and unstable hemodynamic (Table 3). More studies are needed to elucidate the predictors of ICU mortality and ventilatory mode for HM patients with ARF. 
Table 3 Recommendations for HM patients with ARF

\begin{tabular}{ll}
\hline ICU admission & $\begin{array}{l}\text { Giving priority to those who may benefit most from critical care based on an integration of clinical experience, matched } \\
\text { results of clinical studies and the willing of patients and their relatives. More studies are needed to verify predictors, such as } \\
\text { SOFA, APACHEII, SAPSII and others }\end{array}$ \\
Optimal setting & Hematological ICU is preferred, or General ICU where hematologist, intensivist and respiratory therapist can collaborate closely \\
NIV & PaO2/FiO2 $>200 ;$ SO2 $<90 \%$ and RR $>25 ;$ Pulmonary edema; Refuse intubation \\
IMV & PaO2/FiO2 $\leq 200 ; R R>35 ;$ Consciousness disorder; unstable hemodynamic; ARDS; MOD
\end{tabular}

ICU intensive care unit, SOFA sequential organ failure assessment, APACHE acute physiology and chronic health evaluation, SAPS simplified acute physiology Score, NIV noninvasive ventilation, $\mathrm{PaO}_{2}$ arterial oxygen tension, $\mathrm{FiO}_{2}$ fraction of inspired oxygen, $\mathrm{SO} 2$ oxygen saturation, $R R$ respiratory rate, $I M V$ invasive mechanical ventilation, $A R D S$ acute respiratory distress syndrome, MOD multiple organ dysfunction

\section{Acknowledgements}

Not applicable.

\section{Authors' contributions}

LJ wrote the initial drafts. QFW drew the flow chart and table, HBM revised the review and finalized the last version of the article. All authors checked and approved the final version. All authors read and approved the final manuscript.

\section{Funding}

Not applicable.

\section{Availability of data and materials}

Not applicable.

\section{Declarations}

\section{Ethics approval and consent to participate}

This article does not contain any studies with human participants or animals performed by any of the authors.

\section{Consent for publication}

All the authors agree to publishing in EJMR.

\section{Competing interests}

The authors declare that they have no competing interests.

\section{Author details}

${ }^{1}$ Department of Respiratory and Critical Care Medicine, West China Hospital, Sichuan University, Chengdu, China. ${ }^{2}$ Department of Hematology, West China Hospital, Sichuan University, Chengdu, China.

Received: 23 April 2021 Accepted: 6 September 2021

Published online: 17 September 2021

\section{References}

1. Liu J, Bell C, Campbell V, et al. noninvasive ventilation in patients with hematologic malignancy. J Intensive Care Med. 2017;34:197-203.

2. Al-Dorzi HM, Al Orainni H, Al Eid F, et al. Characteristics and predictors of mortality of patients with hematologic malignancies requiring invasive mechanical ventilation. Ann Thorac Med. 2017;12(4):259-65.

3. Squadrone V, Massaia M, Bruno B, et al. Early CPAP prevents evolution of acute lung injury in patients with hematologic malignancy. Intensive Care Med. 2010;36(10):1666-74.

4. Squadrone V, Ferreyra G, Ranieri VM. Non-invasive ventilation in patients with hematologic malignancy: a new prospective. Minerva Anestesiol. 2015;81(10):1118-26.

5. Vadde R, Pastores SM. Management of acute respiratory failure in patients with hematological malignancy. J Intensive Care Med. 2016;31(10):627-41.

6. Namendys-Silva SA, Gonzalez-Herrera MO, Garcia-Guillen FJ, et al. Outcome of critically ill patients with hematological malignancies. Ann Hematol. 2013;92(5):699-705
7. Lemiale $V$, Resche-Rigon M, Mokart D, et al. Acute respiratory failure in patients with hematological malignancies: outcomes according to initial ventilation strategy. A groupe de recherche respiratoire en reanimation onco-hematologique (Grrr-OH) study. Ann Intensive Care. 2015;5(1):28.

8. Lemiale V, Mokart D, Resche-Rigon M, et al. Effect of noninvasive ventilation vs oxygen therapy on mortality among immunocompromised patients with acute respiratory failure: a randomized clinical trial. JAMA. 2015;314(16):1711-9.

9. Azoulay $E$, Pickkers $P$, Soares $M$, et al. Acute hypoxemic respiratory failure in immunocompromised patients: the Efraim multinational prospective cohort study. Intensive Care Med. 2017;43(12):1808-19.

10. Del Sorbo L, Jerath A, Dres M, et al. Non-invasive ventilation in immunocompromised patients with acute hypoxemic respiratory failure. J Thorac Dis. 2016;8(3):E208-216.

11. Azoulay E, Alberti C, Bornstain C, et al. Improved survival in cancer patients requiring mechanical ventilatory support: impact of noninvasive mechanical ventilatory support. Crit Care Med. 2001;29(3):519-25.

12. Khassawneh BY, White P Jr, Anaissie EJ, et al. Outcome from mechanical ventilation after autologous peripheral blood stem cell transplantation. Chest. 2002;121(1):185-8.

13. Fujiwara $Y$, Yamaguchi $H$, Kobayashi K, et al. The therapeutic outcomes of mechanical ventilation in hematological malignancy patients with respiratory failure. Intern Med. 2016;55(12):1537-45.

14. Azoulay E, Mokart D, Pene F, et al. Outcomes of critically ill patients with hematologic malignancies: prospective multicenter data from France and Belgium - a groupe de recherche respiratoire en reanimation onco-hematologique study. J Clin Oncol. 2013;31(22):2810-8.

15. Azoulay E, Pene F, Darmon M, et al. Managing critically III hematology patients: time to think differently. Blood Rev. 2015;29(6):359-67.

16. Mokart D, Lambert J, Schnell D, et al. Delayed intensive care unit admission is associated with increased mortality in patients with cancer with acute respiratory failure. Leuk Lymphoma. 2013;54(8):1724-9.

17. Lengline $E$, Raffoux $E$, Lemiale $V$, et al. Intensive care unit management of patients with newly diagnosed acute myeloid leukemia with no organ failure. Leuk Lymphoma. 2012;53(7):1352-9.

18. Namendys-Silva SA, Garcia-Guillen FJ, Herrera-Gomez A. Opening the doors of the intensive care unit to patients with hematologic malignancies. J Clin Oncol. 2014;32(11):1169-70.

19. Fullerton JN, Perkins GD. Who to admit to intensive care? Clin Med (Lond). 2011;11(6):601-4.

20. Kopterides P, Liberopoulos P, Ilias I, et al. General prognostic scores in outcome prediction for cancer patients admitted to the intensive care unit. Am J Crit Care. 2011;20(1):56-66.

21. Chang L, Horng CF, Huang YC, et al. Prognostic accuracy of acute physiology and chronic health evaluation II scores in critically ill cancer patients. Am J Crit Care. 2006;15(1):47-53.

22. Azoulay E, Mokart D, Lemiale V, et al. Reply to S. A. NAMENDYS-Silva et al. J Clin Oncol. 2014;32(11):1170-1.

23. Soares M, Fontes F, Dantas J, et al. Performance of six severity-of-illness scores in cancer patients requiring admission to the intensive care unit: a prospective observational study. Crit Care. 2004;8(4):R194-203.

24. Lamia B, Hellot MF, Girault C, et al. Changes in severity and organ failure scores as prognostic factors in onco-hematological malignancy patients admitted to the ICU. Intensive Care Med. 2006;32(10):1560-8. 
25. Hilbert G, Boyer A, Vargas F. Optimizing both noninvasive ventilation and antimicrobial approach in hematological patients with acute respiratory failure. Rev Clin Esp. 2014;214(7):385-6.

26. Benoit DD, Depuydt PO, Vandewoude KH, et al. Outcome in severely ill patients with hematological malignancies who received intravenous chemotherapy in the intensive care unit. Intensive Care Med. 2006;32(1):93-9.

27. Benoit DD, Depuydt PO. Non-invasive ventilation in patients with hematological malignancies: the saga continues, but where is the finale? Intensive Care Med. 2010;36(10):1633-5.

28. Grgic Medic M, Gornik I, Gasparovic V. Hematologic malignancies in the medical intensive care unit-Outcomes and prognostic factors. Hematology. 2015;20(5):247-53.

29. Rochwerg B, Brochard L, Elliott MW, et al. Official ERS/ATS clinical practice guidelines: noninvasive ventilation for acute respiratory failure. Eur Respir J. 2017. https://doi.org/10.1183/13993003.02426-2016.

30. Marik PE. Noninvasive positive-pressure ventilation in patients with malignancy. Am J Hosp Palliat Care. 2007;24(5):417-21.

31. Demoule A, Chevret S, Carlucci A, et al. Changing use of noninvasive ventilation in critically ill patients: trends over 15 years in francophone countries. Intensive Care Med. 2016;42(1):82-92.

32. Gristina GR, Antonelli M, Conti G, et al. Noninvasive versus invasive ventilation for acute respiratory failure in patients with hematologic malignancies: a 5-year multicenter observational survey. Crit Care Med. 2011;39(10):2232-9.

33. Piastra M, Antonelli M, Chiaretti A, et al. Treatment of acute respiratory failure by helmet-delivered non-invasive pressure support ventilation in children with acute leukemia: a pilot study. Intensive Care Med. 2004;30(3):472-6.

34. Conti G, Marino P, Cogliati A, et al. Noninvasive ventilation for the treatment of acute respiratory failure in patients with hematologic malignancies: a pilot study. Intensive Care Med. 1998;24(12):1283-8.

35. Barreto LM, Ravetti CG, Athaide TB, et al. Factors associated with non-invasive mechanical ventilation failure in patients with hematological neoplasia and their association with outcomes. J Intensive Care. 2020;8:68.

36. Belenguer-Muncharaz A, Albert-Rodrigo L, Ferrandiz-Selles A, et al. Tenyear evolution of mechanical ventilation in acute respiratory failure in the hematogical patient admitted to the intensive care unit. Med Intensiva. 2013;37(7):452-60.

37. Molina R, Bernal T, Borges $M$, et al. Ventilatory support in critically ill hematology patients with respiratory failure. Crit Care. 2012;16(4):R133.

38. Hilbert G, Gruson D, Vargas F, et al. Noninvasive ventilation in immunosuppressed patients with pulmonary infiltrates, fever, and acute respiratory failure. N Engl J Med. 2001;344(7):481-7.

39. Rathi NK, Haque SA, Nates R, et al. Noninvasivepositive pressure ventilation vsinvasive mechanical ventilation as first-line therapy for acute hypoxemic respiratory failure in cancer patients. J Crit Care. 2017:39:56-61.

40. Saillard C, Mallet D, Chow-Chine L, et al. Non-invasive ventilation indication for critically ill cancer patients admitted to the intensive care unit for acute respiratory failure (ARF) with associated cardiac dysfunction: results from an observational study. PLoS ONE. 2020;15(6):e0234495.

41. Adda M, Coquet I, Darmon M, et al. Predictors of noninvasive ventilation failure in patients with hematologic malignancy and acute respiratory failure. Crit Care Med. 2008;36(10):2766-72.

42. Wermke M, Schiemanck S, Hoffken G, et al. Respiratory failure in patients undergoing allogeneic hematopoietic SCT-a randomized trial on early non-invasive ventilation based on standard care hematology wards. Bone Marrow Transplant. 2012;47(4):574-80.

43. Depuydt PO, Benoit DD, Roosens CD, et al. The impact of the initial ventilatory strategy on survival in hematological patients with acute hypoxemic respiratory failure. J Crit Care. 2010;25(1):30-6.

44. Depuydt PO, Benoit DD, Vandewoude $\mathrm{KH}$, et al. Outcome in noninvasively and invasively ventilated hematologic patients with acute respiratory failure. Chest. 2004;126(4):1299-306.

45. Hilbert G, Gruson D, Vargas F, et al. Noninvasive continuous positive airway pressure in neutropenic patients with acute respiratory failure requiring intensive care unit admission. Crit Care Med. 2000;28(9):3185-90.

46. Lemiale V, Lambert J, Canet $\mathrm{E}$, et al. Identifying cancer subjects with acute respiratory failure at high risk for intubation and mechanical ventilation. Respir Care. 2014;59(10):1517-23.

47. Lee DL, Chiang AA. Outcome and cost of mechanical ventilation in patients with inoperable solid tumors and hematologic malignancies. J Formos Med Assoc. 1995;94(Suppl 2):S120-125

48. Bird GT, Farquhar-Smith P, Wigmore T, et al. Outcomes and prognostic factors in patients with haematological malignancy admitted to a specialist cancer intensive care unit: a 5 yr study. Br J Anaesth. 2012;108(3):452-9.

49. Richards S, Wibrow B, Anstey M, et al. Determinants of 6-month survival of critically ill patients with an active hematologic malignancy. J Crit Care. 2016;36:252-8

50. Groeger JS, White P Jr, Nierman DM, et al. Outcome for cancer patients requiring mechanical ventilation. J Clin Oncol. 1999;17(3):991-7.

51. Barreto LM, Torga JP, Coelho SV, et al. Main characteristics observed in patients with hematologic diseases admitted to an intensive care unit of a Brazilian university hospital. Rev Bras Ter Intensiva. 2015;27(3):212-9.

52. Azoulay E, Mokart D, Lambert J, et al. Diagnostic strategy for hematology and oncology patients with acute respiratory failure: randomized controlled trial. Am J Respir Crit Care Med. 2010;182(8):1038-46.

53. Munshi L, Darmon M, Soares M et al. Acute respiratory failure outcomes in patients with hematologic malignancies and hematopoietic cell transplant: a secondary analysis of the EFRAIM study. Transplant Cell Ther 2021; 27(1): 78 e71-78 e76.

54. Schnell D, Lemiale V, Azoulay E. Non-invasive mechanical ventilation in hematology patients: let's agree on several things first. Crit Care. 2012;16(6):175

55. Correa LC, Teles D, Silva OBD, et al. Predictors of mortality among patients with acute leukemias admitted to an intensive care unit specialized in patients with hematological disease at a Brazilian hospital. Hematol Transfus Cell Ther. 2020:42(1):33-9.

56. Antonelli M, Conti G, Moro ML, et al. Predictors of failure of noninvasive positive pressure ventilation in patients with acute hypoxemic respiratory failure: a multi-center study. Intensive Care Med. 2001;27(11):1718-28.

57. Azoulay E, Lemiale V. Non-invasive mechanical ventilation in hematology patients with hypoxemic acute respiratory failure: a false belief? Bone Marrow Transplant. 2012;47(4):469-72.

58. Truwit JD, Bernard GR. Noninvasive ventilation-don't push too hard. N Engl J Med. 2004;350(24):2512-5.

\section{Publisher's Note}

Springer Nature remains neutral with regard to jurisdictional claims in published maps and institutional affiliations.

Ready to submit your research? Choose BMC and benefit from

- fast, convenient online submission

- thorough peer review by experienced researchers in your field

- rapid publication on acceptance

- support for research data, including large and complex data types

- gold Open Access which fosters wider collaboration and increased citations

- maximum visibility for your research: over 100M website views per year

At $\mathrm{BMC}$, research is always in progress.

Learn more biomedcentral.com/submissions 